\title{
Vilko Nonak
}

Ljubljana

\section{PREDROMANSKE, ROMANSKE IN GERMANSKE BESEDE V SLOVENSKEM GORSKEM PASTIRSTVU}

Lega slovenskega ozemlja prinaša $v$ slovenski jezik besede iz treh jezikovnih skupin. Preteklost našega ozemlja in naroda pa je posrédovala jezikovni substrat in adstrat različnega izvira, predvsem za izraze raznih dejavnosti, $k i$ so izvirale od staroselcer ali pa bile povezane z najstarejšimi sosedi Slovencev. Ena takih dejavnosti, v najstarejših in še $\nabla$ polpreteklih časih izredno pomembna $v$ gorskem svetu, je gorsko pastirstvo ali planšarstvo, planovánje. Sprejeto je mnenje, da je »živinoreja... nesporno tista gospodarska panoga, $\nabla$ kateri so bili pplibi prejšnjega prebinabstoa relativno najmočnejši. Tako so $\mathrm{v}$ živinoreji verjetno ohranjeni razmeroma močni sledovi in ostanki kulture predslovanskega prebivarstra ... $\mathbb{R}^{1}$

Ceprav se pomen te gospodarske panoge čedalje bolj manjša, pa vendarle živijo $\nabla$ njej tudi vsi stari izrazi neslovenskega izvira. Tako značaj našega gorskega pastirstva, kot $z$ njim zvezano izrazje preučujemo natančneje šele $v$ zadnjih desetletjih $v$ zgodovini, geografïji, etnologiji in lingvistiki. Saj se prvi opisovavci pastirskega življenja in dela - zelo zaslužni ljubitelji - niso brigali za izvir starih neslovanskih besed na tem področju, lingvisti pa so žal take opise prezrli ali se niso posvečali raziskovanju tako pomembnega adstrata $v$ našem jeziku. Le redko so se- če so imeli tudi etnološki posluh - ustavljali pri takih besedah, kot npr. M. Murko, ki je pred 70 leti zapisal o besedi $d z g a n$, da je tujega izvira in ljudska etimološka pretvorba, ${ }^{2}$ ob besedi tamar pa je podvomil o »njeni ilirskostik. ${ }^{3}$ Tudi zgodovinarji se niso mnogo zanimali za dogajanje na tem področju $\mathrm{v}$ najstarejših časih, vendar pa je njihovo čast že sorazmerno zgodaj reševal Simon Rutar, ki je v Zgodovini Tolminskega in drugod dokazoval, da so prvi urejali planine $\mathrm{v}$ slovenskih gorah furlanski pastirji in učili Slovence sirarstva, pri čemer je navajal kot dokaz le tri toponime in štiri druge izraze. Povedal je tudi, da so furlanski

1 V. Novak, Živinoreja, v: Gospodarska in družbena zgodovina Slovencev. Zgodovina agrarnih panog 1 . Ljubljana 1970, 371 .

2 M. Murko, Hiša Slovenced, v: Izbrano delo, Ljubljana 1962, 258.

3 N. d. 273-4. 
pastirji, podložniki oglejskega patriarha, ves srednji vek pasli $\mathbf{v}$ gorah, meječih na Kranjsko. ${ }^{4}$ Vemo pa danes tudi, da so furlanski pastirji (v listinah $\gg$ Walchen $\ll$ ) iz okolice Cedada, slovenski pa s Tolminskega prihajali v bohinjske planine. Tako Tolminci kot tudi kmetje iz okolice Radovljice pa so $v$ srednjem veku gonili svoje črede na pašo $v$ Furlanijo na prezimovanje $\mathrm{j}^{5}$ - kar vse govori za tesno sožitje med romanskim in slovenskim življem, ki je moralo zapustiti vidne sledove tako $v$ planšarski tehniki kot v njenem izrazju.

Zaslužni opisovavec pastirskega in alpskega življenja, Henrik Tuma, pa je predstavnik naših ljubiteljev, ki so se podajali na spolzka tla jezikoslovja ter drzno sklepali na podlagi svojih domislic. Trdil je, da so romanski izrazi $\nabla$ našem planšarstvu - slovenski in tujke $v$ - furlanščini, tako Furlani kot Nemci pa naj bi se bili učili planovanja od Slovencev. ${ }^{6}$

Slavist Ivan Koštiál je poznal pet furlanskih besed v slovenskem mlekarskem izrazju in je sklepal, da so se Slovenci od svojih jugozahodnih sosedov $v$ tej panogi marsičega naučili. ${ }^{7}$

Cudno pa je, da je temeljiti geograf Anton Melik, ki je samo planinam $\checkmark$ Julijskih Alpah posvetil célo knjigo, tako prezrl jezikovno stran našega planšarstva ter brez dokazov zavrnil Rutarjevo mnenje, češ da je ostal dolžan dokazov, da so se naši predniki učili planovanja od Furlanov. ${ }^{8}$

S svoje strani se je kot raziskovavec ljudskega pripovedništva približal temu vprašanju Ivan Grafenauer, ki je pokazal zvezo slovenskih pripovedk o ujetem divjem možu-sirarju z retijskim ljudskim izročilom $\mathbf{v}$ švicarskem Kantonu Graubünden. Na to zvezo kaže tudi ime divjega moža Kanih, ki naj bi - po J. Kelemini - bilo sorodno $\mathrm{z}$ imenom gannes za žene divjih mož pri Ladincih. Po I. Grafenauerju se te priporedke nanašajo »na to, kako so se naučili sirarstva od staroselskih Retoromanov v 5. in 6. stol. v Alpe prišli germanski rodovi - lahko pa tudi na to, kako so se naučili planinjenja in sirjenja pri Retijcih in Noričanih keltsko-rimski priseljenci.$^{9}$ To nas zanima zato, ker so se od zadnjih - od Vlahor naučili sirjenja tudi naši alpski predniki.

Prvo skupino »alpskih « besed v slovenščini predstavljajo tedaj predromanske besede in $\mathbf{k}$ njim moramo prištevati tudi predslovenska imena nekaterih naših planin, kot so Komna, Krn, Krma, Matajur, Porezen...

4 S. Rutar, Zgodooina Tolminskega. Ljubljana 1884, 188. - Isti, Kakšno važnost imajo Paola Dijakona knjige, Letopis Matice Slovenske 1885, 288-331.

5 A. Kaspret, Uैber die Lage der oberkrainischen Bauernschaft beim Ausgang des 15. und im Anfange des 16. Jahrhunderts, Mitteilungen des Musealvereins für Krain, 1889, 99.

${ }^{\circ} \mathrm{H}$. Tuma, Naše planine. Jadranski almanah za leto 1924, 92--94.

7 I. Koštiàl, $O$ slopenski in srbohroatski mlekarski ljudski terminologiji. Etnolog XIII, Ljubljana 1940, 127.

8 A. Melik, Planine o Julijskih Alpah. Ljubljana 1900, 68-69.

9 I. Grafenauer, Zoeza slooenskih ljudskih pripooedk z retijskimi. B. Slovenski etnograf XI, 49-68. - Isti, Slovenska pripopedka o ujetem divjem možu. Zgodovinski časopis VI-VII, 124-153 in r. t., VIII, 130-133. 


\section{Vilko Nooak}

Predromanskega izvira je tudi toponim Tamar (konec doline Planice $\checkmark$ Julijskih Alpah in Tamar pri Kranjski gori). Tamar pa je prrotno pomenil preprosto zgradbo s streho iz lubja ali vej ali celo brez nje, $\nabla$ Primorju tudi preprosto kočo za pastirja, na Zilji pa stajo za živino. Zato je pomenilo tamáriti tam, $\mathrm{kjer}$ je tamar bil le ograja za prenočevanje živine: pomikati se s čredo s pašnika na pašnik (Primorsko), da so enakomerno pognojili pašno površino (na Pokljuki imenujejo to gártranje, ker postavljajo gartre - ograjo).10

Težko je določiti, kdaj in od koga so Slovenci prevzeli to besedo. Najbliže nam je misel, da od sosednih Furlanov, s katerimi so imeli od davnine sèm stike in od katerih so prevzeli tudi druge pastirske besede. $V$ furlanščini je tàmar, tàmer 'recinto a stanghe a stecconata o a palizzata, che chiude i varii fabbricati che constituiscono la casera'.11 Besedo pa najdemo še $\mathbf{v}$ drugih romanskih narečjih, npr. v Val Gardeni tàmbra 'Hütte (iz lesa, za seno, drva, ovce), Stecken od. Stangen' iz katerih je bila narejena ograja ali koča. V koroški nemščini Tummer, tunger 'Hürde, Einzäunung, innerhalb welcher das Alpenvieh zur Nachtzeit lagert.' Srlat. je poznala tamuse, furl. tamòssa.

Vse te oblike izvirajo po Hubschmiedu iz predrom. támara 'Schosse, junge Zweige' - predrom. tamno pa je pomenilo - kot dokazujejo romanske oblike, tudi 'stecken', iz česar sklepa Hubschmied, da je tudi predrom. támaro- pomenilo 'Stecken, Stangen', kar potrjuje tudi slovenski pomen besede tamar. ${ }^{12}$

Pravtako stara je beseda médrije, médrija, méder(n)ja za ograjen prostor za živino $\mathrm{v}$ gorah (Goriško), tudi planina Medrija na Tolminskem. Furl. madria; po Hubschmiedu mogoče iz ilir. mandia, prim. grš. $\mu \alpha \dot{v} \delta$ ò, lat. madra.13

$\mathrm{Na}$ Pohorju so poznali besedo tega, teha za pastirsko kočo, kar je retorom. ategia, galsko pa attégia. ${ }^{14}$

Danes $\mathrm{v}$ velikem delu osrednje in zahodne slovenščine uporabljana beseda bajta pomeni tudi planinsko pastirsko kočo in utegne biti prevzeta iz furl. baita ali ital. baita.

Planina Kašina na Krnu je iz ital. cascina (sirarna), rom. pa je tudi ime planine Kuhinja.

Se več besed je romanskega izvira $\mathbf{v}$ zvezi s sirarstvom in mlekarstvom v planinah. Poskusna molža in dan te molže je $v$ Julijskih Alpah

${ }^{10}$ V. Novak, Die Stellung des Alproesens in Sloroenien zroischen dem germanischen und romanischen Raume, v: Volkskunde im Ostalpenraum (= Alpes Orientales II), Graz 1961, 126. - Isti, Živinoreja, gl. op. 1, str. 357.

11 Il Nuovo Pirona, Udine, 1935, 1168.

$12 \mathrm{~J}$. Hubschmied, Vorindogermanische und jüngere Wortschichten in den romanischen Mundarten der Ostalpen. Zeitschrift f. romanische Philologie, LXVI, 23.

13 Isti, Pyrenäenmörter vorromanischen Ursprungs und das romanische Substrat der Alpen, Acta Salmaticensia T. VII, num. 2. Salamanca, 1954.

${ }_{14}$ W. Meyer-Lübke, Romanisches etymologisches Wörterbuch. Heidelberg. 
mizura, furl. mesure, retorom. mesira, masura, mesure $v$ franc. Wallisu (Valais) $\vee$ Švici. ${ }^{15}$ - Pri merjenju mleka uporabljajo poleg drugih posod tudi star - it. stario.

Kotel za sirjenje visi na vratilu - primorsko por - ki mu v Bohinju pravijo dzgan, cgan. Že M. Murko je vedel, da je beseda tuja. Najdemo jo $\mathrm{v}$ retorom. ćigan, ćigona, šigoena, tfigoena, fr. cigogne, špan. cigonel - vse iz lat. ciconia. ${ }^{16}$

Mleko mešajo pri sirjenju s pripravo, ki je bila prvotno obrezana rogovila, najbolje bukova, danes pa je njen vrh iz žične mreže na lesenem ročaju - to je trnáč, furl. tornazzo, kar je bilo verjetno neposredno prevzeto; retorom. taral, tarel, turjet. Ti romanski izrazi pa naj bi se bili razvili iz kontaminacije lat. trusiare + turbulare, katerih koren je kelt. tar--17

Kotel za sirjenje imenujejo $\mathrm{v}$ primorskih planinah skutnik - po skuti, kar je splošno zahodnoslov. beseda za sir iz kravjega mleka, narejen doma, v dolini; $\nabla$ planini pa za sir, narejen iz ostankov sirnine. Furl. je scuete, it. scotta, ben. skuta - vse verjetno iz lat excocta.

Zavreto mleko $\mathrm{v}$ kotlu, sprijemajoče se $\mathrm{v}$ kepice, imenujejo $\mathrm{v}$ primorskih planinah prosnica 'Spriess, Gspriess', prim. ladin. persun, fr. brosse. Pri nas je $H$. Tuma vezal to besedo po ljudski etimologiji s proso. ${ }^{18}$

Tudi $\mathbf{v}$ zvezi z maslarjenjem poznamo nekatere besede romanskega izvira: pinja (zahodno in osrednjeslov.), furl. pigne, iz lat. pinea. Iz te besede: pinjiti, pinjenec, pinjenica, pinjeno mleko - vse 'Buttermilch'. Drugi izraz pa pinjenec je primorsko batuda, iz furl. batude, kar je po križanju z metem dalo matúda (Rož na Koroškem) in metúde (Ziljska dolina in Goriško). ${ }^{19}$

Prvo mleko po otelitvi (sicer slov. mlezivo, mlezovina, mlezva, zmouzva itn.) je ponekod skuta, na Primorskem pa tudi koljâda iz furl. cagliade. ${ }^{20}$ - In končno je osrednjeslov. in knjižno golida (sicer slov. dojilnik, dojača, dojíunica, dojívka itn. ali žehtar iz stvn. sechtari) iz istroital. golida, galeda, iz srlat. galeda. ${ }^{21}$

$\mathrm{Na}$ štajersko-koroškem mejnem območju so imenovali sir iz sladkega mleka (podatek še iz 19. stol.) olaški sir (welscher Käse) in so se ga gotovo naučili izdelovati od Vlahov ali vsaj od Furlanov. ${ }^{22}$

15 R. Weiss, Das Alpmesen Graubündens, Erlenbach-Zürich, 1941, 215 ss. $1935,712$.

${ }_{16}$ J. Jud-K. Jaberg, Sprach- und Sachatlas Italiens und der Südschweiz, Bd. VI. Karte 1211.

17 P. Scheuermeier, Bauernmerk in Italien, der italienischen und rätoromanischen Schmeiz I, Bern, 1942, 39, 120.

18 H. Tuma, gl. op. 6, str. 91.

19 Prim. I. Koštiál, ol. op. 7, str. 127.

20 V. Novak, Uber die Milchmirtschaft bei den Völkern Jugoslaviens, v: Viehwirtschaft und Hirtenkultur, Budapest, 1969, 575.

21 Isti, ibid. 575.

22 F. Kaltenegger, Die Rinderrassen Österreichs, Bd. V. Wien 1897, 129. 


\section{Vilko Nonak}

Poleg teh starih, vsaj srednjeveških besed $v$ zahodni Sloveniji so se ohranile $v$ zaledju Trsta še romanske besede $v$ zvezi s pastirstvom, ki so verjetno novejšega izvira. Tako je turnus obhod, določen na podlagi stehtanih količin mleka, po katerih so se lastniki živine vrstili pri delitvi sira pred odhodom ovac $v$ druge kraje ali pri gmajnski paši. ${ }^{23}$ Trop živine, ki šteje okoli 120 glav ovac, imenujejo čap, iz furl. ciap, s'ciàp, lat. capulum. Poznajo to besedo tudi na hrvaškem primorskem ozemlju $\checkmark$ pomenu »stado ovaca, jato ptica «.24 Stevno enoto po 40 ovac so imenovali kornár, it. quarnaro, hrv. primorsko koarnâr, krnâr, po Skoku istroroman. leksikalni ostanek iz lat. quadragenarium. ${ }^{25}$ Nejasno pa je blek, ki pomeni števno enoto 40 do 50 glav ovac.

Germanskih besed najdemo $\mathbf{v}$ našem pastirskem življenju komaj kaj. Z romanskimi jih veže še najbolj razširjena napa, nafa, ki je pa prišla $v$ germanščino - stvn. napf - iz lat. hanaffus. Pomeni pa leseno posodo za merjenje mleka, ki je obsegala 24 funtor mleka, 4 nape pa so imenovali mezdo, po kateri so se imenovali tisti, ki so namolzli toliko, mezdárji, tisti, ki so namolzli manj od mezde, pa funtarji. Star - iz it. stario - je dal en štih mizure ( $\mathrm{v}$ Reziji mensura), osem štihov ali delov pa je sestavljalo napo. ${ }^{26}$

Sir je sicer tudi germanskega izvira, toda doma tudi $\mathrm{v}$ drugih slovanskih jezikih.

Verjetno je najstarejša germanska beseda $\nabla$ našem planšarstvu ziljska fača, planšarska, pastirska koča. Naši lingvisti je niso razrešili, toda got. fatha, ograja, stena, 27 in srvn. vade, vate, ograja, plot, jasno dokazujeta, da je njen današnji pomen nastal podobno kot pri tamarju.

V zvezi s sirjenjem in njegovimi izdelki moremo omeniti le móhant, móhout - iz nem. s'machet -, kakor imenujejo predvsem ponekod na Gorenjskem sir ali skuto, narejeno iz sirnine, ki je ostala $v$ sirnem kotlu, ko so naredili sir.

\section{Zusammenfassung}

\section{VORROMANISCHE, ROMANISCHE UND GERMANISCHE WORTER} IM SLOWENISCHEN ALPWESEN

Unter den Gebieten der slowenischen Volkskultur, die altertümliche und bedeutende gemeinsame alpenländische Eigenheit aufweisen, ist auch das Alpwesen mit seiner Sach- und Gesellschaftskultur. Der Historiker Simon Rutar

${ }^{23}$ S. Vilfan, Podobe iz nekdanje žioinoreje med Trstom in Slavnikom. Kronika 5, Ljubljana, 1957, 80.

24 P. Skok, Etimologijski rječnik hroatskoga ili srpskoga jezika, II, Zagreb $1972,349$.

25 Ibid. 252.

26 V. Novak, Zivinoreja, gl. op. 1, str. 360 in Die Stellung, gl. op. 10, str. 127.

27 S. Feist, Vergleichendes Wörterbuch der gotischen Sprache, Leiden, 2. Auflage, 1959, 144.

${ }_{28}$ M. Lexer, Mittelhochdeutsches Taschenmörterbuch, Stuttgart, 28. Aufl., 1956, 262. 
hat auf friaulische Hirten hingweisen, die bei den .Slowenen die Käserei eingeführt haben. Henrik Tuma wollte in seinen Beschriebungen des Hirtenlebens keine friaulische Einflüsse zuerkennen. Ähnlich auch der Geograph Anton Melik. Der Linguist Ivan Koštiál untersuchte als einziger den slowenischen Molkereiwortschatz und fand darin fünf friaulische Wörter. Der Philologe und Folklorist Ivan Grafenauer untersuchte den Anteil der Welschen - slow. Vlahi - in der slow. Volksüberlieferung und behauptete in seinen Vergleichungen der slowenischen, deutschen und rätoromanischen Volkssagen über den gefangenen wilden Mann, die die Frage der Käsebereitung in den Ostalpen beleuchten, dass >die Verbindung von den rätisch-alemannischen Fassungen vom wilden Mann, dem Käser, zu den etsprechenden slowenischen... über romanisches Gebiet geht. Und das stimmt ganz mit der südromanischen Nomenklatur der Käsebereitung uiberein.

Vorslowenische Namen einiger Alpen in Slowenien sind:Komna, Krn, Krma, Matajur, Porezen, Trenta... Vielleicht durch friaulische - wenn nicht schon durch welsche - Vermittlung bekamen ihre dem Ursprung nach zwar vorromanischen Namen die Alpen Tamar und Mali Tamar, besonders aber die Alplergebäude tamar, tamor, tamâra, das zuerst einen umzäunten Úbernachtungsplatz, eine Viehhürde oder Pferch bedeutet, später aber auch eine ganz einfache Hütte für die Hirten und das Vieh. Tamáriti bedeutet in Resia: mit der Herde sich ron einem Weideplatz auf einen anderen begeben. Im Kanaltale heisst tamar soviel als stan oder bajta, Alphütte. Es werden romanische Paralellen des Wortes angeführt und auf Hubschmieds vorromanische Ethymologie hingewiesen.

Einen ähnlichen umzäunten Platz bedeutet médrije, médrija, mederja, medernja und eine Alp heisst Medrija. Friaul. madria, nach Hubschmied vielleicht illyr. mandia, griech. mándra, lat. madra. - Ein isolierter Name für Hirtenhiitte ist tega, teha - rätorom. ategia, gallisch attègia. - Friaul. oder ital. Ursprungs ist bajta für Hirtenhiitte.

Der Name einer Alp Kašina führt man aus ital. cascina her.

Das Probemelken und den Melktag nennt man mizura, was friaul. und rätorom. Formen entspricht. - Der Turner für den Kessel heisst cgan, dzgan, vgl. rätorom. ćigan, ćigona etc. - Den Käserührer nennt man in den Julischen Alpen trnáč, vgl. friaul. tornazzo, rätorom. taral, tares, tarai, turjet.

Die erste Milch ist koljáda, aus friaul. cagliade. - Das Butterfass ist pinja, friaul. pigne. Buttermilch batuda, metuda, matuda, friaul. batude.

Ein Schafschar aus ugf. 120 Tiere ist čap - friaul. ciap; von 40 Tiere ist kornár - ital. quarnaro (lat. quadragenarius).

Hölzernes Gefass für Milch ist napa, nafa - ahd. napf, aus lat. hannaffus.

Nur im Gailtal nennt man eine Sehnhütte fača, vgl. got. fatha= Zaun, Scheidewand und mhd. vade. vate = Zaun, Umzäunung. Der Zieger heisst neben skuta auch mohant, mohout - aus deutsch: s'machet. 